\title{
Yüksek viskoziteli cam iyonomer ile kompozit rezinin lastik örtü kullanılmayan oklüzal restorasyonlardaki klinik performansları: 1 yıllık randomize kontrollü bölünmüş ağız çalışması
}

\author{
Hüseyin Hatırlı (iD , ${ }^{\text {* }}$ Bilal Yaşa (iD), \\ Esra Uzer Çelik (iD ${ }^{2}$ \\ ${ }^{1}$ Restoratif Diş Tedavisi Anabilim Dalı, Diş Hekimliği \\ Fakültesi, Tokat Gaziosmanpaşa Üniversitesi, Tokat \\ ${ }^{2}$ Restoratif Diş Tedavisi Anabilim Dalı, Diş Hekimliği \\ Fakültesi, Izmir Katip Çelebi Üniversitesi, İzmir, Türkiye
}

\section{Özet}

AMAÇ: Bu randomize, kontrollü, tek kör, bölünmüş ağız (split-mouth), tek merkezli klinik çalışmanın amacı, lastik örtü kullanılamayan alt ikinci büyük azı dişlerin oklüzal restorasyonlarında yüksek viskoziteli cam iyonomer ile nanohibrit kompozit rezinin bir yıllık klinik performanslarının karşılaştırılmasıdır.

GeREÇ VE YönteM: Bu çalışmada 56 hastanın (26 kadın, 30 erkek) sağ ve sol alt ikinci büyük azı dişlerindeki oklüzal çürükleri bölünmüş ağız tasarımına uygun olarak restore edildi. Yüksek viskoziteli cam iyonomer (EQA; Equia Fil, GC) ve nanohibrit kompozit rezin (GSO; GrandioSo, Voco) üretici firma önerileri doğrultusunda kavitelere uygulandı. Restorasyonların değerlendirilmesi bir hafta, altı ay ve bir yıl sonra FDI kriterlerine göre yapıldı. Verilerin analizi Friedman's ANOVA ve Mann-Whitney U testleri ile gerçekleştirildi $(\alpha=0.05)$.

BULGULAR: Bir yıl sonundaki değerlendirmede, fonksiyonel, estetik ve biyolojik değerlendirme kriterleri göz önüne alındığında 1, 2 ve 3 skoru alan ve başarılı olarak değerlendirilen restorasyonların oranı EQA grubunda \%96 ve GSO grubunda \%100 idi. Altıncı ay ve bir yıldaki değerlendirmelerde GSO grubunun EQA grubuna göre anlamlı derecede daha iyi yüzey parlaklığına sahip olduğu belirlendi $(p<0.05)$. Materyallerin bir yıl içerisindeki değişimleri değerlendirildiğinde ise, GSO grubunda yüzey parlaklığı, yüzey renklenmesi ve kenar uyumu açısından anlamlı ölçüde değişim olduğu ( $p<0.017$; Bonferroni düzeltmeli Wil-

Makale gönderiliş tarihi: 18 Eylül 2020; Yayına kabul tarihi: 21 Şubat 2021 * lletişim: Dr. Hüseyin Hatırlı, Tokat Gaziosmanpaşa Üniversitesi Diş Hekimliği Fakültesi, Restoratif Diş Tedavisi Anabilim Dalı, 60030,Tokat, Türkiye; E-posta: huseyinhatirli@gmail.com coxon işaretli sıralar testi), EQA grubunda ise yüzey parlaklığı ve kenar uyumu açısından anlamlı değişim olduğu görüldü $(p<0.017)$.

SonUç: Lastik örtü kullanılmayan alt ikinci büyük azı dişlerine uygulanan oklüzal restorasyonlarda yüksek viskoziteli cam iyonomer ile nanohibrit kompozit rezin bir yıl sonunda kabul edilebilir klinik başarı gösterdi.

Anahtar Kelimeler: Cam iyonomer; diş çürükleri; kompozit dental rezin

Kaynak Göstermek İçin: Hatırlı H, Yaşa B, Uzer Çelik E. Yüksek viskoziteli cam iyonomer ile kompozit rezinin lastik örtü kullanılmayan oklüzal restorasyonlardaki klinik performansları: 1 yıllık randomize kontrollü bölünmüş ağız çalışması. Acta Odontol Turc 2021;38(3):68-74

KLiniK Araştırma Kayıt Bilgisi: NCT04488380; https:// clinicaltrials.gov/ct2/show/NCT04488380

EDiтöR: Güven Kayaoğlu, Gazi Üniversitesi, Ankara, Türkiye

YAYIN HAKKI: () 2021 Hatırlı ve ark. Bu eserin yayın hakkı Creative Commons Attribution License ile ruhsatlandırılmıştır. Sınırsız kullanım, dağıtım ve her türlü ortamda çoğaltım, yazarlar ve kaynağın belirtilmesi kaydıyla serbesttir.

Finansal Destek: Bulunmamaktadır.

ÇıKAR ÇATıŞMASI: Bulunmamaktadır.

[Abstract in English is at the end of the manuscript]

\section{Giriş}

Kompozit rezinler, minimal kavite preparasyonuna olanak sağlaması, diş dokularını taklit edebilen optik özellikleri, iyi mekanik özellikleri ve indirekt restorasyonlara göre uygulama kolaylığı bulunması nedeniyle günümüzde direkt posterior restorasyonlarda en çok tercih edilen restoratif materyallerdir. Bununla birlikte, kompozit rezinlerle diş dokularına istenilen düzeyde bir bağlanma sağlanabilmesi için adeziv sistemlerin uygulama aşamalarının özenle gerçekleştirilmesi çok önemlidir. Adezivlerle iyi bir bağlantı sağlanabilmesi için diş yüzeyinin tükürük ve ağız sıvıları ile kontaminasyonun 
engellenmesi şarttır. Mine veya dentin yüzeyinin kontamine olması, adezivin bağlantı yüzeyi ile etkili bir şekilde temasını engeller. Tükürük içerisindeki proteinler mikro düzeydeki boşlukları tıkayarak ve su da adeziv polimerizasyonunu engelleyerek bağlanmayı olumsuz etkiler. ${ }^{1,2}$

İzolasyonun yeterli bir şekilde sağlanamadığı durumlarda kompozit rezinlere alternatif materyallerin kullanımı düşünülebilir. Tükürükle kontaminasyonun, cam iyonomerlerin mine ve dentine bağlanma dayanımını değiştirmediği ve mikrosızıntısını etkilemediği rapor edilmiştir. ${ }^{3,4}$ Amalgam estetik olmaması, diş dokularında fazla madde kaybına neden olması ve çevreye zararlı etkisi nedeniyle giderek daha az tercih edilmektedir. $^{5}$

Restoratif olarak kullanılabilen cam iyonomer içerikli materyaller; rezin modifiye cam iyonomer simanlar, poliasit modifiye kompozit rezinler (kompomerler), yüksek viskoziteli cam iyonomer simanlar ve giomerlerdir. Bu materyaller arasından en avantajlısı çiğneme kuvvetlerine dayanıklı olması ve uygulama kolaylığı nedeniyle yüksek viskoziteli cam iyonomerlerdir. Rezin içerikli cam iyonomerlerin aksine yüksek viskoziteli cam iyonomerlerde kaviteye adeziv sistem uygulamasına gerek yoktur. Yüksek viskoziteli cam iyonomerlerde cam partiküllerinin yüzeyindeki fazla kalsiyum iyonları uzaklaştırılmış, partikül boyutları, dağılımı ve toz/likit oranı değiştirilmiştir. ${ }^{6}$ Bu sayede fiziksel ve mekanik özellikleri iyileştirilen yüksek viskoziteli cam iyonomerler daha hızı ıir sertleşme reaksiyonuna sahiptir. Ayrıca materyalin erken dönemdeki suya maruziyeti fiziksel özelliklerini olumsuz yönde etkilememektedir. ${ }^{7}$ Yüksek viskoziteli cam iyonomerlerin fiziksel ve mekanik özellikleri giderek iyileştirilmesine rağmen, iki ve çok yüzlü kavitelerde kullanımları hala tartışmalıdır. Oklüzal kavitelerde ise güvenle uygulanabildikleri bildirilmiştir.

Kompozit rezinlerle restore edilecek dişlerde izolasyon başlangıç aşamasından bitim aşamasına kadar kritik öneme sahiptir. İzolasyon için en ideal yöntem lastik örtü kullanımıdır. Ancak lateks alerjisi, burundan solunum güçlüğü, astım veya psikolojik nedenlerden dolayı hasta lastik örtü uygulamasını tolere edemeyebilir ya da dişin lastik örtü tutucusunu destekleyecek oranda sürmemiş olması da lastik örtü uygulamasını olanaksız

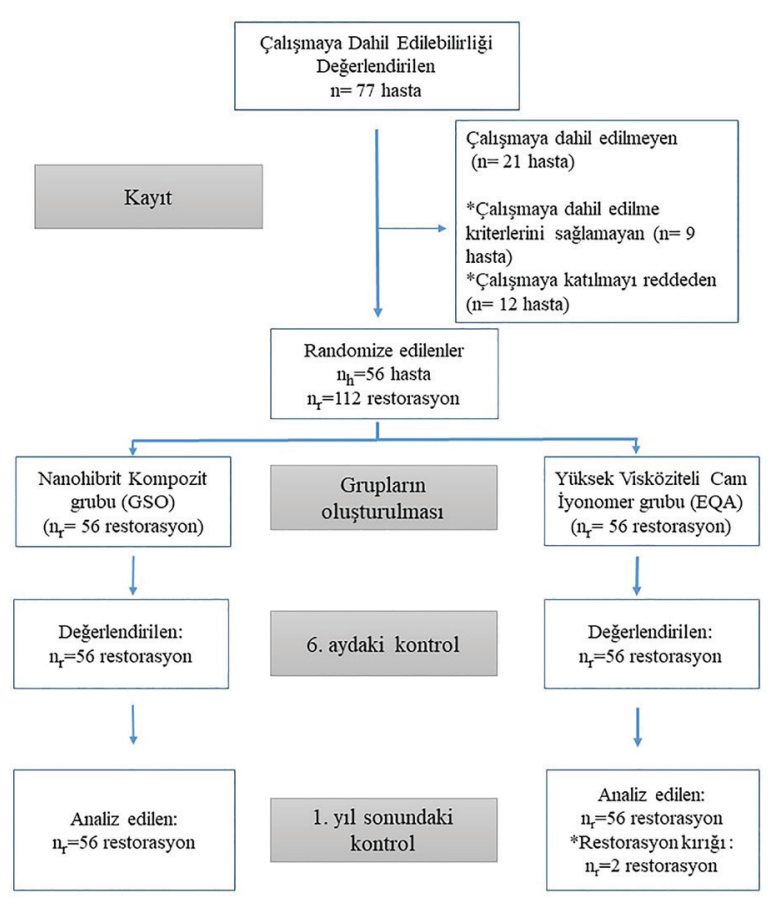

Şekil 1. Çalışma şeması, $n_{h}$; hasta sayısı, $n_{r}$; restorasyon sayısı

hale getirebilir. ${ }^{8} \mathrm{Bu}$ durumda pamuk rulo, selüloz plaka ve tükürük emici kullanımı ile izolasyon sağlanmaya çalışılabilir.

Tedavi sırasındaki hasta pozisyonu ve yer çekimine bağlı olarak tükürüğün alt azılar bölgesinde göllenmesi ve pamuk ruloların yanak ve dil tarafında hareketsiz kalmasındaki zorluklar izolasyon açısından önemli ölçüde problem oluşturmaktadır. Bunun yanı sıra literatürde, gençlerin (18-40 yaş) tükürük akış hızının ilaç kullanımından bağımsız olarak yaşılıardan (60 yaş üstü) anlamlı ölçüde daha fazla olduğu bildirilmektedir. ${ }^{9} \mathrm{Bu}$ nedenlerden dolayı, lastik örtü kullanılamadığında izolasyonda en çok zorlanılan durumlar tükürük akış hızı fazla olan genç hastalarda ve alt çenenin en gerisinde yer alan dişlerde restorasyon yapılmasıdır. İzolasyon açısından riskli hastalarda, bağlanma performansı, fiziksel ve mekanik özellikleri olası tükürük kontaminasyonundan daha az etkilenen restoratif materyaller ile daha uzun ömürlü restorasyonlar yapılabilir.

Tablo 1. Araştırmada kullanılan materyaller ve içerikleri

\begin{tabular}{|c|c|c|}
\hline Materyal & İçerik & Üretici \\
\hline $\begin{array}{l}\text { Clearfil SE Bond } \\
\text { (Bağlayıcı ajan) }\end{array}$ & $\begin{array}{l}\text { Primer: MDP, HEMA, hidrofilik dimetakrilat, polimerizasyon başlatıcı, su } \\
\text { Adeziv: MDP, HEMA, Bis-GMA, hidrofobik dimetakrilat, polimerizasyon } \\
\text { başlatıcı, silanlanmış kolloidal silika }\end{array}$ & Kuraray, Tokyo, Japonya \\
\hline $\begin{array}{l}\text { GrandioSO } \\
\text { (Nanohibrit kompozit rezin) }\end{array}$ & $\begin{array}{l}\text { BisGMA, BisEMA, TEGDMA, Cam seramik }(1.0 \mu \mathrm{m}) \text {, silikon dioksit } \\
\text { nanopartikül }(20-40 \mathrm{~nm}) \text {, demir oksit, titanium oksit }\end{array}$ & $\begin{array}{l}\text { VOCO, Cuxhaven, } \\
\text { Almanya }\end{array}$ \\
\hline Cavity Conditioner & $\% 20$ Poliakrilik asit & GC, Tokyo, Japonya \\
\hline $\begin{array}{l}\text { Equia Fil } \\
\text { (Yüksek vizkoziteli cam iyonomer) }\end{array}$ & Poliakrilik asit, alumina-silikat cam, distile su & GC, Tokyo, Japonya \\
\hline Equia Coat (Yüzey koruyucu rezin) & Metil metakrilat, kolloidal silika, kamforokinon & GC, Tokyo, Japonya \\
\hline
\end{tabular}

Bis-GMA: Bis fenol A glisidil dimetakrilat; HEMA: 2-hidroksietil metakrilat; MDP: 10-metakrilloloksidesill dihidrojenfosfat; UDMA: Üretandimetakrilat; Bis-EMA: bisfenol A polietilen glikol dieter dimetakrilat; TEGDMA: trietilenglikoldimektarilat 
Tablo 2. FDI değerlendirme kriterlerine ${ }^{8}$ ve kontrol zamanlarına göre restorasyonların aldığı skorlar

\begin{tabular}{|c|c|c|c|c|c|c|c|c|c|c|}
\hline & & \multicolumn{3}{|c|}{ Başlangıç } & \multicolumn{3}{|c|}{ 6. ay } & \multicolumn{3}{|c|}{ 1. yıl } \\
\hline & & GrandioSo & Equia Fil & p-değeri§ & GrandioSo & Equia Fil & p-değeri§ & GrandioSo & Equia Fil & p-değeri§ \\
\hline & & $\begin{array}{c}\text { Skor } \\
1 / 2 / 3 / 4 / 5\end{array}$ & $\begin{array}{c}\text { Skor } \\
1 / 2 / 3 / 4 / 5\end{array}$ & & $\begin{array}{c}\text { Skor } \\
1 / 2 / 3 / 4 / 5\end{array}$ & $\begin{array}{c}\text { Skor } \\
1 / 2 / 3 / 4 / 5\end{array}$ & & $\begin{array}{c}\text { Skor } \\
1 / 2 / 3 / 4 / 5\end{array}$ & $\begin{array}{c}\text { Skor } \\
1 / 2 / 3 / 4 / 5\end{array}$ & \\
\hline \multirow{4}{*}{ 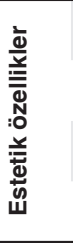 } & $\begin{array}{l}\text { Yüzey } \\
\text { parlaklığı }\end{array}$ & $53 / 3 / 0 / 0 / 0$ & $54 / 2 / 0 / 0 / 0$ & 0.649 & $46 / 10 / 0 / 0 / 0$ & $31 / 25 / 0 / 0 / 0$ & 0.002 & $40 / 16 / 0 / 0 / 0$ & $15 / 39 / 0 / 0 / 0$ & 0.000 \\
\hline & $\begin{array}{l}\text { Yüzey } \\
\text { renklenmesi }\end{array}$ & $56 / 0 / 0 / 0 / 0$ & $56 / 0 / 0 / 0 / 0$ & 1.000 & $53 / 3 / 0 / 0 / 0$ & $53 / 3 / 0 / 0 / 0$ & 1.000 & $50 / 6 / 0 / 0 / 0$ & $50 / 4 / 0 / 0 / 0$ & 0.509 \\
\hline & $\begin{array}{l}\text { Kenar } \\
\text { renklenmesi }\end{array}$ & $56 / 0 / 0 / 0 / 0$ & $56 / 0 / 0 / 0 / 0$ & 1.000 & $54 / 2 / 0 / 0 / 0$ & $55 / 1 / 0 / 0 / 0$ & 0.560 & $54 / 2 / 0 / 0 / 0$ & $52 / 2 / 0 / 0 / 0$ & 1.000 \\
\hline & $\begin{array}{l}\text { Anatomik } \\
\text { form }\end{array}$ & $43 / 13 / 0 / 0 / 0$ & $41 / 15 / 0 / 0 / 0$ & 0.556 & $42 / 14 / 0 / 0 / 0$ & $35 / 21 / 0 / 0 / 0$ & 0.396 & $40 / 16 / 0 / 0 / 0$ & $30 / 24 / 0 / 0 / 0$ & 0.227 \\
\hline \multirow{3}{*}{ 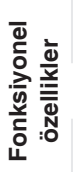 } & $\begin{array}{l}\text { Kırık ve } \\
\text { retansiyon }\end{array}$ & $56 / 0 / 0 / 0 / 0$ & $56 / 0 / 0 / 0 / 0$ & 1.000 & $56 / 0 / 0 / 0 / 0$ & $56 / 0 / 0 / 0 / 0$ & 1.000 & $54 / 2 / 0 / 0 / 0$ & $50 / 3 / 1 / 2 / 0$ & 0.134 \\
\hline & Kenar uyumu & $55 / 1 / 0 / 0 / 0$ & $55 / 1 / 0 / 0 / 0$ & 1.000 & $54 / 2 / 0 / 0 / 0$ & $51 / 5 / 0 / 0 / 0$ & 0.244 & $49 / 7 / 0 / 0 / 0$ & $45 / 8 / 1 / 0 / 0$ & 0.291 \\
\hline & Aşınma & $56 / 0 / 0 / 0 / 0$ & $56 / 0 / 0 / 0 / 0$ & 1.000 & $56 / 0 / 0 / 0 / 0$ & $55 / 1 / 0 / 0 / 0$ & 0.317 & $56 / 0 / 0 / 0 / 0$ & $52 / 2 / 0 / 0 / 0$ & 0.080 \\
\hline \multirow{2}{*}{ 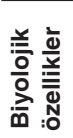 } & $\begin{array}{l}\text { Postoperatif } \\
\text { hassasiyet }\end{array}$ & $56 / 0 / 0 / 0 / 0$ & $56 / 0 / 0 / 0 / 0$ & 1.000 & $56 / 0 / 0 / 0 / 0$ & $56 / 0 / 0 / 0 / 0$ & 1.000 & $56 / 0 / 0 / 0 / 0$ & $54 / 0 / 0 / 0 / 0$ & 1.000 \\
\hline & $\begin{array}{l}\text { Sekonder } \\
\text { çürük }\end{array}$ & $56 / 0 / 0 / 0 / 0$ & $56 / 0 / 0 / 0 / 0$ & 1.000 & $56 / 0 / 0 / 0 / 0$ & $56 / 0 / 0 / 0 / 0$ & 1.000 & $56 / 0 / 0 / 0 / 0$ & $54 / 0 / 0 / 0$ & 1.000 \\
\hline
\end{tabular}

§Mann-Whitney U testi $(p<0.05)$

$\mathrm{Bu}$ randomize, kontrollü, tek kör, bölünmüş ağız (split-mouth), tek merkezli klinik çalışmanın amacı, lastik örtü kullanılmayan alt ikinci büyük azı dişlerin oklüzal restorasyonlarında bir yüksek viskoziteli cam iyonomer ile bir adet nanohibrit kompozit rezinin bir yıllık klinik performanslarının karşılaştırılmasıdır. Çalışmada 'fonksiyonel, estetik ve biyolojik kriterler açısından değerlendirilen restorasyon materyalleri arasında fark yoktur' sıfır hipotezi test edilmiştir.

\section{Gereç Ve Yöntem}

\section{Araştırmanın niteliği ve örneklem büyüklüğü}

Çalışmada tedavi edilecek hasta sayısını belirlemek için G*Power (G*Power Ver. 3.0.10, Franz Faul, Üniversität Kiel, Almanya) paket programı kullanıldı. Yüksek viskoziteli cam iyonomer ve nanohibrit kompozit rezin arasındaki f=0.25'lik (orta derecede) etki farkını \%80 güç ile belirleyebilmek için $a=0.05$ tip I hata düzeyinde, her bir grup için en az 47 restorasyona intiyaç olduğu belirlendi. Uzun takip süresi boyunca oluşabilecek hasta kayıplarından kaynaklanan bilgi kaybını ve çalışmanın gücünün düşmesini engellemek amacı ile her iki gruba \%20 (9'ar) yedek eklenerek grup başına 56 restorasyon ile çalışmaya başlanmasına karar verildi.

İzmir Katip Çelebi Üniversitesi Diş Hekimliği Fakültesi Restoratif Diş Tedavisi kliniğine başvuran 18 yaşından küçük 77 hasta bu çalışmaya dahil edilmek üzere muayene edildi. Çalışmaya dahil edilme kriterlerine uygun olmayan 21 hasta çalışmaya dahil edilmedi. Ortalama yaşları 16.8 olan toplam 56 hasta (26 kadın, 30 erkek) çalışmaya dahil edildi (Şekil 1). Araştırma Helsinki Deklarasyonu Prensiplerine uygun olarak yapıldı ve araştırma protokolü İzmir Katip Çelebi Üniversitesi Tıp Fakültesi Etik Kurulunca onaylandı (Etik Kurul
No: 13-93). Uygulanacak olan tedavi işlemleri ve olası riskler hasta ve yasal temsilcisine anlatıldıktan sonra bilgilendirilmiş gönüllü onam formu çalışmanın başında hastaların yasal temsilcilerine onaylatıldı.

\section{Hasta seçimi}

Çalışmaya dahil edilme kriterleri; (1) 18 yaşından küçük olup, alt ikinci büyük azı dişleri oklüzal düzleme ulaşmış hastalar, (2) iyi genel sağlığa sahip olma, (3) iyi ağız hijyenine sahip olma, (3) alt ikinci büyük azı dişlerde restorasyon olmaması, (4) alt ikinci büyük azı dişlerin meziyal ve oklüzal kontakta olması, (5) alt ikinci büyük azı dişlerde oklüzal çürük varlığı, (6) diş pozisyonu, hasta uyumsuzluğu ve hastanın lastik örtü kullanımını reddetmesi sebepleriyle lastik örtü takılamayan hastalar, (7) çalışma süresince düzenli olarak kontrollere gelebilme olarak belirlendi. Çalışmaya dahil edilmeme kriterleri ise; (1) şiddetli periodontal hastalık, (2) ortodontik maloklüzyona bağlı aşırı yük altında olan veya oklüzyon dışında kalan alt ikinci büyük azı dişlerin varı̆̆ı olarak belirlendi, (3) parafonksiyonel alışkanlıklara sahip olma, (4) sigara kullanma.

Bu çalışmaya katılan kırk hasta veya hastanın yasal temsilcisi lastik örtü kullanımını reddetti, sekiz hastada hasta uyumsuzluğu sebebiyle ve sekiz hastada ise diş pozisyonu ve klemp retansiyonunun sağlanamaması sebebiyle lastik örtü kullanılamadı.

\section{Lezyon seçimi ve dişlerin gruplara dağıtılması (ran- domizasyon)}

Klinik muayenede Uluslararası Çürük Tespit ve Değerlendirme Sistemi (ICDAS) skorlarına göre sağ ve sol alt ikinci büyük azı dişlerinin her ikisinde de 3 veya 4 skorları alan [minede beyaz ya da kahverengi lezyon ile lokal kırılmaların bulunduğu, dentinin açıkta olmadığı (skor 3) ya da açığa çıktığı (skor 4)], orta derinlikte ok- 
Tablo 3. Değerlendirilen restoratif materyallerin 6 ay ve 1 yıl kontrollerinde başlangıca göre kendi içindeki değişimi

\begin{tabular}{|c|c|c|c|c|}
\hline \multirow[t]{2}{*}{ Değerlendirme kriteri } & & \multirow[t]{2}{*}{ Materyal } & \multicolumn{2}{|c|}{ Değerlendirme periyodu, p-değerleris } \\
\hline & & & Başlangıç-6 ay & Başlangıç-1 yıl \\
\hline \multirow[t]{8}{*}{ Estetik özellikler } & Yüzey parlaklığı & GrandioSo & 0.080 & 0.001 \\
\hline & & Equia Fil & 0.000 & 0.000 \\
\hline & Yüzey renklenmesi & GrandioSo & 0.083 & 0.014 \\
\hline & & Equia Fil & 0.083 & 0.046 \\
\hline & Kenar renklenmesi & GrandioSo & 0.157 & 0.157 \\
\hline & & Equia Fil & 0.317 & 0.157 \\
\hline & Anatomik form & GrandioSo & 1.000 & 0.157 \\
\hline & & Equia Fil & 0.317 & 0.025 \\
\hline \multirow[t]{6}{*}{ Fonksiyonel özellikler } & Kırık ve retansiyon & GrandioSo & 1.000 & 0.157 \\
\hline & & Equia Fil & 1.000 & 0.042 \\
\hline & Kenar uyumu & GrandioSo & 0.317 & 0.014 \\
\hline & & Equia Fil & 0.046 & 0.002 \\
\hline & Aşınma & GrandioSo & 1.000 & 1.000 \\
\hline & & Equia Fil & 0.317 & 0.083 \\
\hline \multirow[t]{4}{*}{ Biyolojik özellikler } & Postoperatif hassasiyet & GrandioSo & 1.000 & 1.000 \\
\hline & & Equia Fil & 1.000 & 1.000 \\
\hline & Sekonder çürük & GrandioSo & 1.000 & 1.000 \\
\hline & & Equia Fil & 1.000 & 1.000 \\
\hline
\end{tabular}

lüzal dentin çürüğü bulunan hastalar bu çalışmaya dahil edildi. Restore edilecek dişlerin gruplara atanması için Excel programında randomizasyon tablosu hazırlandı. Her hastanın sağ ve sol alt ikinci azı dişleri ile gruplar oluşturuldu ve randomizasyon tablosu doğrultusunda dişler rastgele olarak yüksek viskoziteli cam iyonomer ve kompozit rezin gruplarına atandı.

\section{Restorasyonların uygulanması}

Tüm restoratif işlemler deneyimli bir diş hekimi (H.H.) tarafından Ekim 2015 - Nisan 2016 tarihleri arasında uygulandı. Öncelikle tüm hastalara ağız hijyen eğitimi verildi ve profesyonel ağız bakımı yapıldı. Diş yüzeylerindeki yumuşak doku eklentileri flor içermeyen bir pat ile temizlendi. Lezyonların başlangıç fotoğrafları ekartör ve ağız aynası yardımı ile dijital fotoğraf makinası (D7100, Nikon Corp, Tokyo, Japonya) ile alındı. Mine dokusu yuvarlak uçlu elmas frezle, çürük dentin dokusu ise tungsten-karbit frezlerle (frez no: 801-014 ve 801-018) uzaklaştıııdı, sağlıklı diş dokusu korunacak şekilde minimal invaziv kavite preperasyonu yapıldı. Restorasyon uygulanması sırasında izolasyon pamuk peletler ve tükürük emici ile sağlandı.

Yüksek viskoziteli cam iyonomer materyali (EQA; Equia Fil, GC, Tokyo, Japonya) uygulamasında, önce Cavity Conditioner (GC) mine ve dentine 10 sn uygulandı, hava-su spreyi ile yıkandı ve hafifçe kurutuldu. Kapsül içerisindeki materyal 10 sn karıştırıldı ve tek tabaka olarak kaviteye uygulandı. Bitirme işlemi ve yükseklik kontrolü sonrasında cam iyonomer yüzey verniği (Equia Coat, GC) uygulandı ve $1200 \mathrm{~mW} / \mathrm{cm}^{2}$ güçteki LED ışık cihazı (Valo, Ultradent, South Jordan, UT, $A B D$ ) ile 20 sn ışıkla sertleştirildi.

Kompozit rezin yerleştirilmeden önce adeziv sistem olarak Clearfil SE Bond (Kuraray, Tokyo, Japonya) üretici önerileri doğrultusunda uygulandı. Primer tüm diș yüzeyine 20 sn boyunca bir fırça yardımı ile uygulandı, orta şiddetli hava ile çözücü uzaklaştırıldı. Adeziv fırça ile uygulanarak, hafif șiddetli hava ile kaviteye yayıldı ve $10 \mathrm{sn}$ ışıkla polimerize edildi. Restoratif materyal olarak GrandioSo (GSO; Voco GmbH, Cuxhaven, Almanya) $2 \mathrm{~mm}$ 'lik tabakalar halinde uygulandı ve her tabaka 20 sn ışıkla polimerize edildi. Yükseklik kontrolü ve bitim işlemi sarı kuşakı elmas frezler ile yapıldı. Restorasyonlar kompozit parlatma lastikleri ile (Astropol, Ivoclar, Schaan, Liechtenstein) parlatılarak bitirildi.

\section{Restorasyonların değerlendirilmesi}

Restorasyonların kontrolleri ve değerlendirilmesi uygulama aşamasında yer almayan ve kalibrasyonları çalışma öncesinde sağlanmış iki deneyimli gözlemci (B.Y., E.U.C..) tarafından bir hafta, altı ay ve bir yıl sonra FDI kriterlerine göre yapıldı. ${ }^{10}$ Fonksiyonel (materyalde kırık veya retansiyon problemi, kenar uyumu, aşınma), estetik (yüzey parlaklı̆̆ı, yüzey renklenmesi, kenar renklenmesi, estetik anatomik form) ve biyolojik (postoperatif hassasiyet, sekonder çürük) kriterleri 1'den 5'e kadar skorlandı. Bir, 2 ve 3 skorları klinik olarak kabul edilebilir olarak değerlendirilirken, 4 ve 5 skorlarını alan restorasyonlar başarısız olarak kabul edildi. Değerlendiriciler arasında anlaşmazlık olduğu durumlarda tekrar değerlendirme ile ortak bir karara varıldı. Gözlemciler arası ve gözlemci içi uyumu sırasıyla $\% 82$ ve $\% 88$ idi.

\section{İstatistiksel değerlendirme}

İstatistiksel analizler SPSS 22 (IBM-SPSS Inc, Chicago, IL, ABD) programı kullanılarak yapıldı. Her bir değerlendirme kriteri için restoratif materyallerin farklı zamanlardaki karşılaştırmaları Mann-Whitney U testi ile yapıldı. Sonuçlar \%95 güven aralığında değerlendirildi $(a=0.05)$. Materyal gruplarının kendi içinde zamana göre karşılaştııılmasında Friedman testi ve ikili karşılaştırmalarda ise Bonferroni düzeltmeli Wilcoxon işaretli 
sıralar testi kullanıldı. Bonferroni düzeltmesi sonrasında anlamlılık değeri mümkün olan karşılaştırma sayısına bölünerek anlamlılık değeri belirlendi $(p<0.017)$.

\section{BULGULAR}

Hastaların tamamı bir hafta, altı ay ve bir yıl sonra kontrol edildi (Resim 1). Restorasyon uygulamasından sonraki değerlendirmeler boyunca hiçbir hastanın postoperatif hassasiyet yaşamadığı ve değerlendirilen restorasyonların hiçbirinde sekonder çürük gelişmediği belirlendi. Bir haftalık değerlendirmede EQA ve GSO grupları arasında estetik, fonksiyonel ve biyolojik değerlendirme kriterleri açısından fark bulunmadı ( $p>0.05)$.

Altı ay sonraki değerlendirmede ise, GSO grubunun EQA grubuna göre anlamlı derecede daha iyi yüzey parlaklığına sahip olduğu belirlendi $(p<0.05)$. Diğer değerlendirme kriterleri açısından materyaller arasında fark yoktu. Başlangıç ve altı aylık skorlar karşılaştırıldığında GSO grubunda farklılık izlenmezken, EQA gru- bunda yalıızca yüzey parlaklığında altıncı ayda anlamlı ölçüde azalma olduğu belirlendi $(p<0.017)$.

Bir yıl sonundaki değerlendirmede, fonksiyonel, estetik ve biyolojik değerlendirme kriterleri göz önüne alındığında; 1, 2 ve 3 skoru alan ve başarılı olarak değerlendirilen restorasyonların oranı EQA grubunda \%96 ve GSO grubunda \%100 idi. EQA grubunda iki restorasyon, materyalde kırık veya retansiyon kriteri için başarısız skor (skor 4) aldı (Resim 2). Bununla birlikte, GSO grubunda hiçbir restorasyonun başarısız skoru almadığı görüldü. Yüzey parlaklığı açısından GSO grubunun altıncı ayda olduğu gibi anlamlı ölçüde daha iyi olduğu belirlenirken $(p<0.05)$, diğer değerlendirme kriterleri açısından materyaller arasında fark gözlenmedi. Materyallerin bir yıl içerisindeki değişimleri incelendiğinde ise, GSO grubunda yüzey parlaklığı, yüzey renklenmesi ve kenar uyumu açısından anlamlı değişim oluştuğu görüldü ( $p<0.017)$. EQA grubunda ise yüzey parlaklığı ve kenar uyumu kriterleri açısından anlamlı değişim olduğu belirlendi $(p<0.017)$.
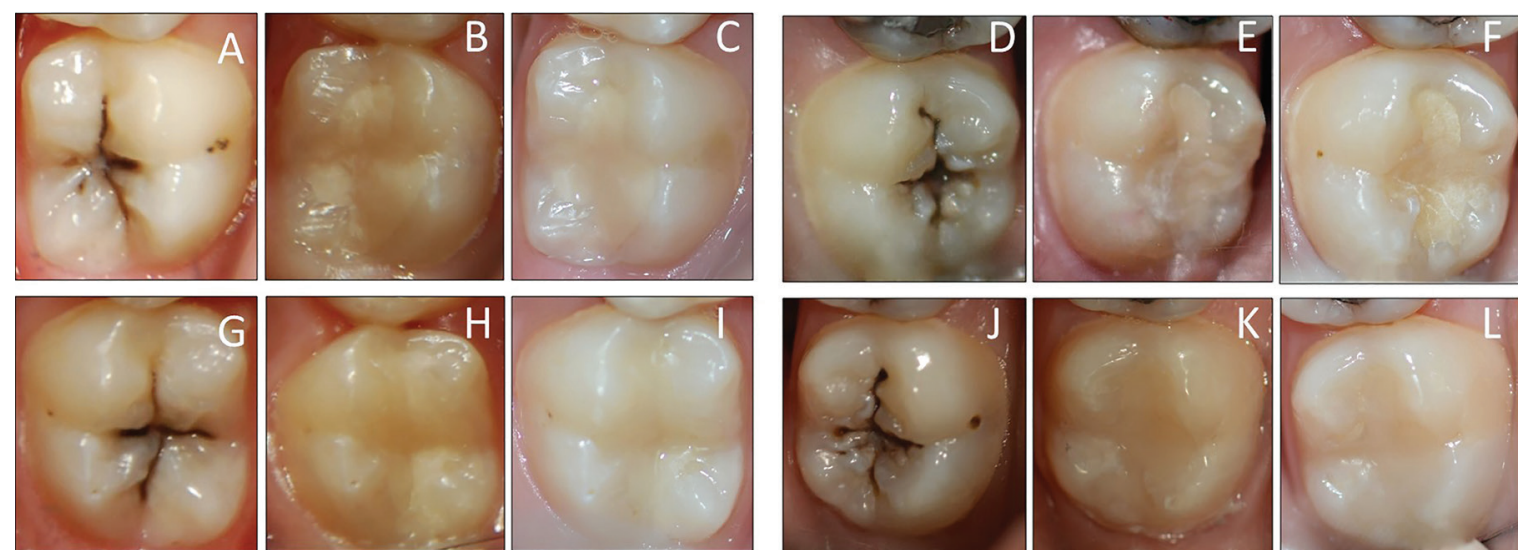

Resim 1. Calıșmada değerlendirilen restorasyonların restorasyon öncesi, restorasyon sonrası ve 12 aylık kontrol fotoğraflarından örnekler; $(A, D)$ Yüksek viskoziteli cam iyonomer restorasyonların restorasyon öncesi, (B, E) Yüksek viskoziteli cam iyonomer restorasyonların restorasyon sonrası, (C, F) Yüksek viskoziteli cam iyonomer restorasyonların 12 aylık kontrolü, (G, J) Nanohibrit kompozit restorasyonların restorasyon öncesi, (H, K) Nanohibrit kompozit restorasyonların restorasyon sonrası, (I, L) Nanohibrit kompozit restorasyonların 12 aylık kontrolü
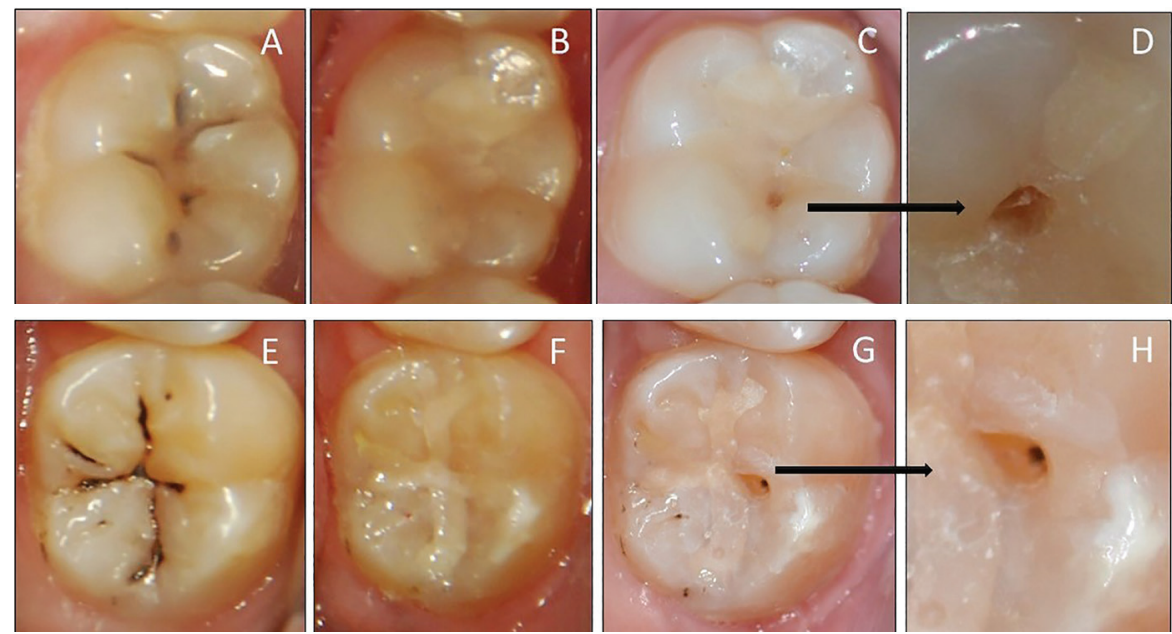

Resim 2. Birinci yıl kontrolünde başarısız olarak değerlendirilen restorasyonların restorasyon öncesi $(A, E)$, restorasyon sonrası $(B, F)$, birinci yıl $(C, G)$ ve başarısızlık yaşanan bölgelerin büyütülmüş fotoğrafları $(D, H)$ 


\section{TARTIŞMA}

Restoratif materyallerin klinik başarılarının değerlendirilmesi açısından klinik çalışmalar büyük öneme sahiptir. ${ }^{11-13}$ Yüksek viskoziteli cam iyonomerler adeziv sisteme gerek duyulmadan hızlı ve kolay şekilde hafif nemli mine ve dentine bağlanabilir. Bu avantaj izolasyonun çoğunlukla zor olduğu ağız ortamına yeni sürmüş alt ikinci büyük azı dişlerinin restorasyonunda kolaylık sağlayabilir. Bu nedenle, bu çalışmada lastik örtü kullanılamayan hastaların alt ikinci büyük azılardaki oklüzal restorasyonlarda yüksek viskoziteli cam iyonomer ile nanohibrit kompozit rezinin klinik başarılarının karşılaştırıması amaçlanmıştır.

Bir yıllık değerlendirme sonucunda nanohibrit kompozit restorasyonların yüksek viskoziteli cam iyonomer restorasyonlara göre anlamlı ölçüde daha iyi yüzey parlaklığı sergilediği gözlendi. Bu nedenle çalışmanın 'fonksiyonel, estetik ve biyolojik kriterler açısından değerlendirilen restorasyon materyalleri arasında farklıık yoktur' sıfır hipotezi, kısmen reddedilmiştir.

Cam iyonomer içerikli restorasyon materyallerinde yüzey cilasının istenilen derecede sağlanamaması bir dezavantaj olarak görülmektedir. ${ }^{14,15}$ Ancak bu çalışmada, başlangıç yüzey parlaklığı açısından gruplar arasında farklılık bulunmamaktadır. Yüksek viskoziteli cam iyonomer yüzeyine uygulanan yüzey verniği, restorasyonlarda pürüzsüz bir yüzey oluşturulmasına yardımcı olmaktadır. Bunun yanı sıra, altıncı aydan itibaren cam iyonomerlerin yüzey parlaklığında azalma olduğu belirlenmiştir. Bu durumun cam iyonomerlerin yüksek porözite içermesi ve düşük aşınma direncine sahip rezin içerikli verniğin aşınarak yüzeyden uzaklaşmasından kaynaklandığı düşünülmektedir. ${ }^{11,13}$ Benzer şekilde, Çelik ve arkadaşları da sınıf $\mathrm{V}$ restorasyonlarda yüksek viskoziteli cam iyonomerlerin başarısını değerlendirdikleri çalışmada, bu materyalin yüzey pürüzlülüğünde zamanla artış olduğunu ve 3 yıl sonunda yüksek viskoziteli cam iyonomer restoratif materyalin yüzey pürüzlülüğünün kompozitten anlamlı ölçüde daha fazla olduğunu rapor etmişlerdir. ${ }^{16}$

Diğer taraftan, bir yıl sonundaki değerlendirmede nanohibrit kompozit grubunda da yüzey parlaklığının anlamlı şekilde azaldığı görülmüştür. Kompozit rezinlerin doldurucu boyutları ve bileşiminin restorasyonların yüzey pürüzlülüğüne etkisi bilinmektedir. ${ }^{17}$ GrandioSo nano-hibrit içerikli bir kompozittir ve doldurucu olarak silikon dioksit nanopartikül (20-40 nm) ile cam seramik $(1 \mu \mathrm{m})$ içermektedir. Ağız içerisindeki aşındırıcı kuvvetlerin etkisi ile organik matrisin aşınması ve $1 \mu \mathrm{m}$ boyutundaki cam seramik doldurucuların açığa çıkmasının bir yılsonunda kompozit restorasyonlardaki yüzey parlaklığı kaybına neden olduğu düşünülmektedir. Yazıcı ve arkadaşları da cila işleminin hemen sonrasında dahi GrandioSo kompozit materyalinde yüzey pürüzlülüğünün değerlendirilen diğer kompozitlerden daha yüksek olduğunu bildirmişlerdir. ${ }^{18}$ Bunun yanısıra, yüzey pürüzlülüğündeki artışla beraber, restorasyonlarda yüzey renklenmesi ve kenar renklenmesinin de zamanla arttlğı izlenmektedir.
Restorasyonda kenar uyumunun bozularak kenar renklenmesinin artması, mikrosızıntı gelişmesine ve restorasyonun kaybına zemin hazırlayan durumlardır. ${ }^{19}$ $\mathrm{Bu}$ çalışmada, bir yıl sonunda total restorasyon kaybı izlenmezken, EQA grubunda iki restorasyonda parsiyel olarak restorasyon kaybı görülmüş ve başarısız olarak değerlendirilmiştir. Ancak istatistiksel değerlendirme sonucunda materyaller arasında anlamlı fark olmadığı görülmüştür. Benzer şekilde, güçlendirilmiş cam iyonomerlerin sınıf I ve sınıf II restorasyonlardaki başarısının değerlendirildiği bir çalışmada, bir yıl sonunda tüm sınıf I restorasyonların başarılı bulunduğu belirtilmiştir. ${ }^{11}$ Hastaların ağız bakımı alışkanlıkları ve çürüğe yatkınlıkları ile restorasyonların uygulanma şartları klinik çaIışmalarda sonuçlara etki edebilmektedir. ${ }^{20}$

Mandibular ikinci büyük azı dişlerin restorasyonunda kavite izolasyonu, özellikle tükürük akış hızının fazla olduğu genç hastalarda zorluk oluşturabilir. Lastik örtü uygulaması izolasyon açısından en güvenilir yöntem olsa da söz konusu dişlerin özellikle distal bölgelerindeki kısa klinik kuron boyu, sürmesini tamamlamamış dişlerde tutucuların yerleştirilememesi veya hasta iş birliğinin bulunmaması uygulamayı engellemektedir. $\mathrm{Bu}$ nedenle çalışmada kavitelerin izolasyonu pamuk peletler ve tükürük emici ile sağlanmıştır. Uygulama basamaklarının az olması sayesinde yüksek viskoziteli cam iyonomer restorasyon daha hızlı gerçekleştirilerek izolasyon probleminin olası etkileri azaltılmıştır. Diğer yandan, GrandioSo grubunda adeziv uygulaması, tabakalı olarak kompozit uygulaması, bunların ışıkla polimerizasyonu daha fazla zaman almış ve izolasyon güçlükle sağlanabilmiştir. Kısa dönemde materyaller arasında fark oluşturmayan bu durumun etkilerini değerlendirmek için uzun dönem klinik takibe ihtiyaç duyulmaktadır. Ancak olası farkların sadece izolasyon probleminden değil, materyal özelliklerinden de kaynaklanabileceği de dikkate alınmalıdır.

Restorasyonlarda zamanla meydana gelen aşınmanın gözlemciler tarafından nitel olarak değerlendirilmesi bu çalışmanın sınırılıklarından biridir. Ancak literatürde belirtildiği şekilde ${ }^{10}$, restorasyonlar uygulandıktan sonra alınan fotoğraflar altı ay ve bir yıl sonraki kontrollerde referans alınarak restorasyonların aşınması değerlendirilmiştir. Bu çalışmanın bir diğer sınırlıı̆ı ise, kavite boyutlarının standardizasyonu amacıyla yalnızca ICDAS'a göre sınıf 3 ve 4 olarak skorlanmış orta derinlikte oklüzal kavitelerin çalışmaya dahil edilmiş olmasıdır. Lastik örtünün uygulanamayıp oklüzalde kavite boyutlarının arttığı veya arayüzlere uzandığı durumlarda yapılan restorasyonların performanslarının değerlendirildiği ileri çalışmalara intiyaç duyulmaktadır.

\section{SonUç}

Bir yıllık değerlendirme sonucunda, lastik örtü kullanılamayan alt ikinci büyük azı dişlerinin oklüzal restorasyonlarında, yüksek viskoziteli cam iyonomer ile nanohibrit kompozit rezin kabul edilebilir klinik başarı gösterdi. Yüksek viskoziteli cam iyonomerin hızlı uygulama ile 
iyi derecede estetik özelliklere sahip olma avantajları bulunmaktadır. Ancak, daha uzun süreli klinik takip ve gözlemlere intiyaç duyulmaktadır.

\section{TEŞEKKÜR VE ANMA}

İstatistiksel değerlendirmedeki yardımlarından dolayı Dr. Hakan Hatırlı'ya ve Dr. Osman Demir'e teşekkür ederiz.

\section{KAYNAKLAR}

1. Nair $P$, Hickel $R$, llie $N$. Adverse effects of salivary contamination for adhesives in restorative dentistry. A literature review. Am J Dent 2017;30:156-64.

2. Van Meerbeek B, Van Landuyt K, De Munck J, Inoue S, Yoshida Y, Perdigao J, et al. Bonding to enamel and dentin. In: Summitt JB, Robbins JW, Hilton TJ, Schwartz RS, editors. Fundamentals of Operative Dentistry: A Contemporary Approach. 3rd ed. Chicago: Quintessence; 2006. p. $183-260$

3. Kulczyk K, Sidhu S, McCabe J. Salivary contamination and bond strength of glass-ionomers to dentin. Oper Dent 2005;30:676-83.

4. Shimazu K, Karibe H, Ogata K. Effect of artificial saliva contamination on adhesion of dental restorative materials. Dent Mater $\mathrm{J}$ 2014;33:545-50.

5. Pereira T. Silver amalgam: A clinician's perspective. J Res Dent 2016;4:25-30

6. Lohbauer U, Krämer N, Siedschlag G, Schubert EW, Lauerer B, Mueller FA, et al. Strength and wear resistance of a dental glass-ionomer cement with a novel nanofilled resin coating. Am J Dent 2011;24:124-8.

7. Wang XY, Yap AU, Ngo HC. Effect of early water exposure on the strength of glass ionomer restoratives. Oper Dent 2006;31:584-9.

8. Donovan TE, Eidson S. Instruments and equipment for tooth preparation. In: Roberson T, Heymann HO, Swift Jr EJ, editors. Sturdevant's Art and Science of Operative Dentistry. 6th ed. St. Louis: Mosby; 2006. p.164-85

9. Affoo RH, Foley N, Garrick R, Siqueira WL, Martin RE. Meta-Analysis of Salivary Flow Rates in Young and Older Adults. J Am Geriatr Soc 2015;63:2142-51

10. Hickel R, Peschke A, Tyas M, Mjör I, Bayne S, Peters M, et al. FDI World Dental Federation: clinical criteria for the evaluation of direct and indirect restorations-update and clinical examples. Clin Oral Investig 2010;14:349-66.

11. Turkun LS, Kanik O. A Prospective Six-Year Clinical Study Evaluating Reinforced Glass lonomer Cements with Resin Coating on Posterior Teeth: Quo Vadis? Oper Dent 2016;41:587-98.

12. Gurgan S, Kutuk ZB, Ergin E, Oztas SS, Cakir FY. Clinical performance of a glass ionomer restorative system: a 6-year evaluation. Clin Oral Investig 2017;21:2335-43.

13. Lohbauer U, Kramer N, Siedschlag G, Schubert EW, Lauerer B, Muller FA, et al. Strength and wear resistance of a dental glass-ionomer cement with a novel nanofilled resin coating. Am J Dent 2011;24:124-8.

14. Ulrich L. Dental Glass Ionomer Cements as Permanent Filling Materials. Properties, Limitations and Future Trends. Materials 2010;3:7696.

15. Scholtanus JD, Huysmans MC. Clinical failure of class-II restorations of a highly viscous glass-ionomer material over a 6-year period: a retrospective study. J Dent 2007;35:156-62

16. Celik EU, Tunac AT, Yilmaz F. Three-year clinical evaluation of high-viscosity glass ionomer restorations in non-carious cervical lesions: a randomised controlled split-mouth clinical trial. Clin Oral Investig 2019;23:1473-80

17. Jung M, Eichelberger K, Klimek J. Surface geometry of four nanofiller and one hybrid composite after one-step and multiple-step polishing. Oper Dent 2007;32:347-55.
18. Yazici AR, Tuncer D, Antonson S, Onen A, Kilinc E. Effects of delayed finishing/polishing on surface roughness, hardness and gloss of tooth-coloured restorative materials. Eur J Dent 2010;4:50-6.

19. Letzel $\mathrm{H}$. Survival rates and reasons for failure of posterior composite restorations in multicentre clinical trial. J Dent 1989;17:10-7.

20. Arhun N, Celik C, Yamanel K. Clinical evaluation of resin-based composites in posterior restorations: two-year results. Oper Dent 2010;35:397-404.

\section{Clinical performance of high-viscosity glass ionomer and resin composite on occlusal restorations performed without rubber-dam isolation: a one-year randomized controlled split-mouth study}

\begin{abstract}
OBJECTIVE: The aim of this randomized, controlled, single-blind, split-mouth and single-center clinical trial was to compare the one-year clinical performances of a high viscosity glass ionomer and a nano-hybrid composite resin on occlusal restorations of mandibular second molar teeth performed without rubber dam isolation.

MAterials ANd Method: Occlusal carious lesions on right and left mandibular second molars of 56 patients (26 female, 30 male) were restored according to a split-mouth design in this study. A high viscosity glass ionomer (EQA; Equia Fil, GC) and a nano-hybrid composite resin (GSO; GrandioSo, Voco) were applied according to the manufacturers' instructions. Clinical evaluation of the restorations was performed according to the FDI criteria at one-week, six-month, and one-year follow-ups. The data were statistically analyzed using Friedman's ANOVA and Mann-Whitney $U$ tests $(\alpha=0.05)$.
\end{abstract}

RESULTS: After one year, considering functional, esthetic, and biological criteria, the rate of restorations scored with 1,2 , and 3 , and were evaluated as successful was $96 \%$ in the EQA group, and $100 \%$ in the GSO group. GSO showed significantly better surface luster than EQA at both sixmonth and one-year follow-ups $(p<0.05)$. When one-year alterations within the materials were considered; surface luster, surface discoloration, and marginal adaptation scores significantly increased in the GSO group $(p<0.017$; Wilcoxon signed-rank test with Bonferroni correction). On the other hand, the scores of surface luster and marginal adaptation significantly increased in the EQA group $(p<0.017)$.

ConCLusion: One-year performance of high viscosity glass ionomer and nano-hybrid composite on occlusal restorations of mandibular second molars were considered acceptable without rubber-dam isolation.

KEYWORDS: Glass ionomer; dental caries; composite dental resin 